\title{
Nano-sized Silicalite-1: novel route of synthesis, metal impregnation and its application in selective oxidation of toluene
}

\author{
MAAZ NAWAB, SUNITA BAROT and RAJIB BANDYOPADHYAY* \\ Department of Science, School of Technology, Pandit Deendayal Petroleum University, Raisan, Gandhinagar, \\ Gujarat 382 007, India \\ E-mail: rajib.bandyopadhyay@ sot.pdpu.ac.in
}

MS received 29 August 2018; revised 1 November 2018; accepted 6 November 2018; published online 19 December 2018

\begin{abstract}
The novel route of synthesis and catalytic performance of nano-sized Silicalite-1 are presented. Nano-sized Silicalite-1 was initially obtained from a clear solution using sodium silicate as silica source and tetrapropylamonium hydroxide as a template. The effects of silica source on the product yield, purity, crystallization rate and crystallinity were investigated. Effect of seeds in the synthesis was also studied. Nucleation time decreased to $6 \mathrm{~h}$ from $24 \mathrm{~h}$ using $4 \%$ seed, with yield and crystallinity $70 \%$ and $90 \%$, respectively. The catalyst was characterized by XRD, FE-SEM, TG, FITR and $\mathrm{N}_{2}$ adsorption-desorption techniques. Transition metals like $\mathrm{Fe}, \mathrm{Cu}$ and Mo were impregnated by wet impregnation method. $\mathrm{Cu}$-impregnated nanosized Silicalite-1 was found to be highly active for the oxidation of toluene with $\mathrm{H}_{2} \mathrm{O}_{2}$.
\end{abstract}

Keywords. Nano-sized Silicalite-1; toluene oxidation; liquid phase; zeolite.

\section{Introduction}

The selective oxidation of organic compounds is considered as a crucial transformation in organic synthesis. Benzaldehyde is used as a raw material or intermediate in pharmaceutical, ${ }^{1}$ perfumery, ${ }^{2}$ dyestuff, agrochemicals and plastic industries. Toluene can be oxidized into several derivatives such as benzyl alcohol, benzaldehyde, benzoic acid, etc., in which benzaldehyde is the essential industrially used aromatic aldehyde among all the oxidized products. The chlorination of toluene and hydrolysis of benzylchloride are the conventional industrial processes for the production of benzaldehyde, which generally cause chlorine contamination that directly affects the production of benzaldehyde. Some of the drawbacks of this process are harsh conditions, formation of toxic acid, tedious and expensive separation procedure and lower yield of benzaldehyde. ${ }^{3}$ Vapor phase reaction at high temperature and pressure is the alternate oxidation method for toluene with the flow of oxygen. However, the mentioned method seems too difficult for the improvement of benzaldehyde selectivity. ${ }^{4,5}$
Liquid phase oxidation of toluene using potential oxidizing agents like air, organic peroxides, hydrogen peroxide, etc., provide better scope to the industrial processes under mild reaction conditions. Several methods are reported with the homogeneous catalysts such as iridium(III) chloride, ${ }^{6}$ metal complexes, ${ }^{7-9}$ 10-methyl-9-phenylacridinium ion, ${ }^{10}$ xanthone, ${ }^{11}$ and polyoxometalate. ${ }^{12}$ Some other heterogeneous catalysts are also reported for this reaction such as supported metal complexes ${ }^{13-15}$ and metal containing molecular sieves. ${ }^{16-20}$ Song et $a l .{ }^{21}$ reported oxidation of toluene over copper nanoparticle supported graphene. Compared to other organic oxidants, hydrogen peroxide is widely used in liquid phase oxidation reactions due to its easy handling, cost-effectiveness and environment-friendly qualities. Du et al. ${ }^{22}$ have used sodium treated ZSM-5 and Li et al., ${ }^{23}$ have used various iron-supported zeolites along with the use of hydrogen peroxide as an oxidant for the oxidation of toluene. There are other reports available using hydrogen peroxide along with metal-loaded/metal-free zeolites like $[\mathrm{Cu} \text { (terpy) }]^{2+} @ \mathrm{Y}, \mathrm{Co}_{3} \mathrm{O}_{4} @ \mathrm{HZSM}-5, \mathrm{Sn}-$ Beta, Fe/ZSM-5, TS-1, VS-1, Sn-Silicalite-1(MFI),

\footnotetext{
*For correspondence

Electronic supplementary material: The online version of this article (https://doi.org/10.1007/s12039-018-1579-0) contains supplementary material, which is available to authorized users.
} 
Sn-Silicalite-2(MEL), Sn-MTW, metal free Silicalites, Sn-ZSM-12, ZSM-12, Sn-ZSM-48 (Al free), etc. ${ }^{24-33}$

As the crystal size of zeolite reduces, all other associated properties like external surface area, surface charge, and ionic charge show remarkable enhancement. These changes enable the reaction of bulky molecules on the zeolite surface, which is not possible due to the microporous nature of zeolite crystal. The transport of the molecules from the surface to the center of the crystals is a slow process due to the presence of these narrow pores. Consequently, adsorption and reaction occur primarily at the outer shell of the zeolite crystals while the interior is hardly used, reducing the total effectiveness of the zeolite catalyst and limiting the effect of the pore selectivity for reactants or products. In order to utilize the entire zeolite crystal and to decrease the total adsorption/desorption time, one can lower these diffusion limitations by using smaller crystal size, e.g., nanocrystals, or by the synthesis of mesoporous zeolites. It is also possible to combine zeolite with other binders and supports, and increase its usability in other fields. ${ }^{34-36}$

Silicalite-1 has a pentagonal 10-membered ring structure. The framework is a combination of two intersecting channels; one elliptical-shaped straight channel with a cross section $0.53 \mathrm{~nm} \times 0.56 \mathrm{~nm}$, and another zig-zag channel with cross section $0.51 \mathrm{~nm}$ $\times 0.55 \mathrm{~nm} .{ }^{37}$ Here, we report the synthesis of nanosized Silicalite-1, and selective oxidation of toluene over metal-impregnated nano-sized Silicalite-1 using hydrogen peroxide as an oxidant in a liquid phase at mild condition.

The novelty of the present study is the synthesis of nano-sized Silicalite-1 using $\mathrm{H}_{3} \mathrm{PO}_{4}$ as a promoter in minimum time with good crystallinity as well as exploring the effect of metal impregnated nanosized Silicalite-1 as a catalyst in the oxidation of toluene.

\section{Experimental}

\subsection{Materials}

Tetra propyl ammonium hydroxide (TPAOH, $40 \mathrm{wt} \%$ solution) was procured from Tritech Catalyst and Intermediate Pvt. Ltd. Sodium silicate $\left(26.7 \% \mathrm{SiO}_{2}, 14.4 \% \mathrm{Na}_{2} \mathrm{O}\right)$ and phosphoric acid (85\%) was procured from SD Fine Chem. Ltd. Ferric nitrate (98\%), copper nitrate (98\%), ammonium heptamolybdate $(97 \%)$, acetonitrile $(99 \%)$, toluene $(99 \%)$ and hydrogen peroxide (30\% solution) were purchased from Merck. All the chemicals were of analytical grade and used as obtained without further purification.

\subsection{Catalyst synthesis}

Synthesis of nano-sized Silicalite-1 was carried out with the molar gel composition $1 \mathrm{SiO}_{2}$ : $0.25 \mathrm{TPAOH}: 1.042 \mathrm{NaOH}$ : $0.271 \mathrm{H}_{3} \mathrm{PO}_{4}: 30 \mathrm{H}_{2} \mathrm{O}$ and was prepared by mixing water, TPAOH and $\mathrm{H}_{3} \mathrm{PO}_{4}$ to Na-Silicate solution. The $\mathrm{pH}$ of the final gel was adjusted at 11.5 by adding $\mathrm{H}_{3} \mathrm{PO}_{4} \cdot \mathrm{H}_{3} \mathrm{PO}_{4}$ was added as a promoter to reduce the synthesis time and obtain good crystallinity in a short time period which has not been explored so far for the Silicalite-1 system. The synthesis gel was further stirred for $4 \mathrm{~h}$ at room temperature. The hydrothermal synthesis was carried out at $160^{\circ} \mathrm{C}$ for $24 \mathrm{~h}$ until complete crystallization. The nanocrystals were collected by centrifugation. After discarding the supernatant liquid, the solid product was recovered, dried at $90^{\circ} \mathrm{C}$ overnight, followed by calcination at $550^{\circ} \mathrm{C}$ for $5 \mathrm{~h}$.

Copper nitrate, Ferric nitrate and ammonium heptamolybdate were used as a source of metal and doped on nano-sized Silicalite- 1 by wet impregnation technique. An aqueous solution of each metal source containing 3\% transition metal ions was stirred at room temperature with nano-sized Silicalite1 for $1 \mathrm{~h}$ and the solution was evaporated to dryness. The solid was dried and grinded at $100{ }^{\circ} \mathrm{C}$ overnight followed by calcination for $5 \mathrm{~h}$ at $550^{\circ} \mathrm{C}$.

\subsection{Effect of seed amount on crystallization time}

Effect of seed amount on the hydrothermal synthesis of nanosized Silicalite- 1 was studied by taking different seed weight percentage in terms of $\mathrm{SiO}_{2}$. Initially, $4 \%$ seed was fixed with varying the hydrothermal synthesis time (i.e., $10 \mathrm{~h}, 18 \mathrm{~h}, 24 \mathrm{~h}$, and $30 \mathrm{~h}$ ) to study the crystal growth and crystallinity of the Silicalite-1. The yield of the product at $10 \mathrm{~h}$ was very less compared to $18 \mathrm{~h}$. Further synthesis time $(18 \mathrm{~h})$ was fixed and seed amount was varied in terms of $\mathrm{SiO}_{2}$ (i.e., $1 \%, 2 \%, 3 \%$, and $4 \%$ ) to study the growth and crystallinity of the nanosized Silicalite-1 (Table 1).

\subsection{Oxidation of toluene}

Oxidation of toluene was carried out in an RB flask equipped with reflux condenser and magnetic stirrer. Catalyst, acetonitrile and toluene were added in the desired proportion and

Table 1. Effect of seed on crystallization time.

\begin{tabular}{lcccc}
\hline No. & $\begin{array}{c}\text { Seed } \\
\text { amount }\end{array}$ & $\begin{array}{c}\text { Crystallization } \\
\text { time (h) }\end{array}$ & \% Yield & $\begin{array}{c}\text { \% Relative } \\
\text { crystallinity }\end{array}$ \\
\hline 1 & - & 24 & 65 & 100 \\
2 & $1 \%$ & 18 & 65 & 92 \\
3 & $1 \%$ & 12 & 54 & 90 \\
4 & $2 \%$ & 18 & 74 & 93 \\
5 & $2 \%$ & 12 & 67 & 85 \\
6 & $3 \%$ & 18 & 79 & 92 \\
7 & $3 \%$ & 12 & 69 & 91 \\
8 & $4 \%$ & 6 & 70 & 90 \\
\hline
\end{tabular}



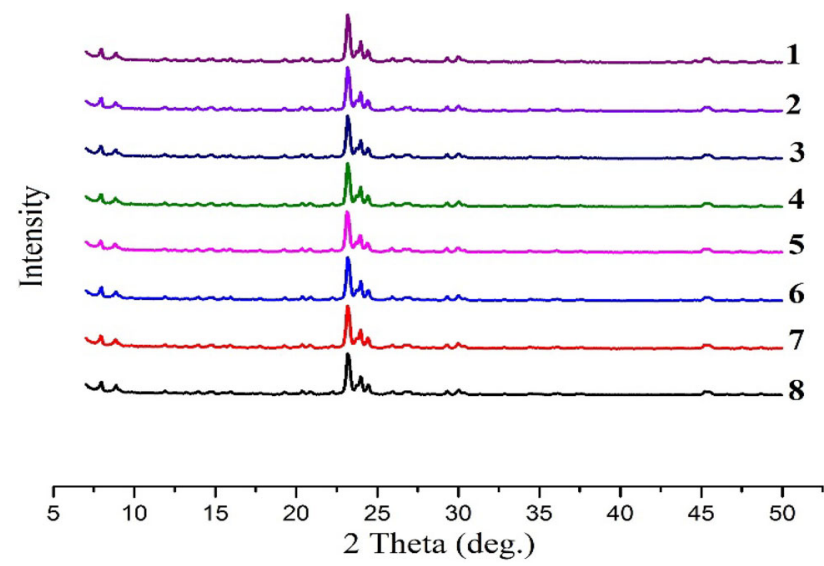

Figure 1. XRD of Silicalite-1; Pattern number corresponds to entry number in Table 1.

heated at the set temperature. Hydrogen peroxide was added dropwise to the reaction mixture at regular intervals. Reaction samples were drawn at regular time intervals and analyzed using GC (Shimadzu 2025). The solid catalyst was separated by centrifugation while liquid samples were injected to GC with HP5 capillary column and FID detector. Conversion of toluene and yield of benzaldehyde were measured by manual calibration curve method. Product identification was done over GCMS (Agilent 7890).

\section{Results and Discussion}

\subsection{Characterization of catalyst}

Figure 1 shows the XRD patterns of nano-sized Silicalite-1 (pattern number corresponds to an entry in Table 1), which confirm the MFI structure. Seed concentration on the reaction time reveals that pure MFI phase with good crystallinity was obtained in minimum reaction time of $6 \mathrm{~h}$ by using $4 \%$ seed with a good yield. Yield increased to $79 \%$ using $3 \%$ seed

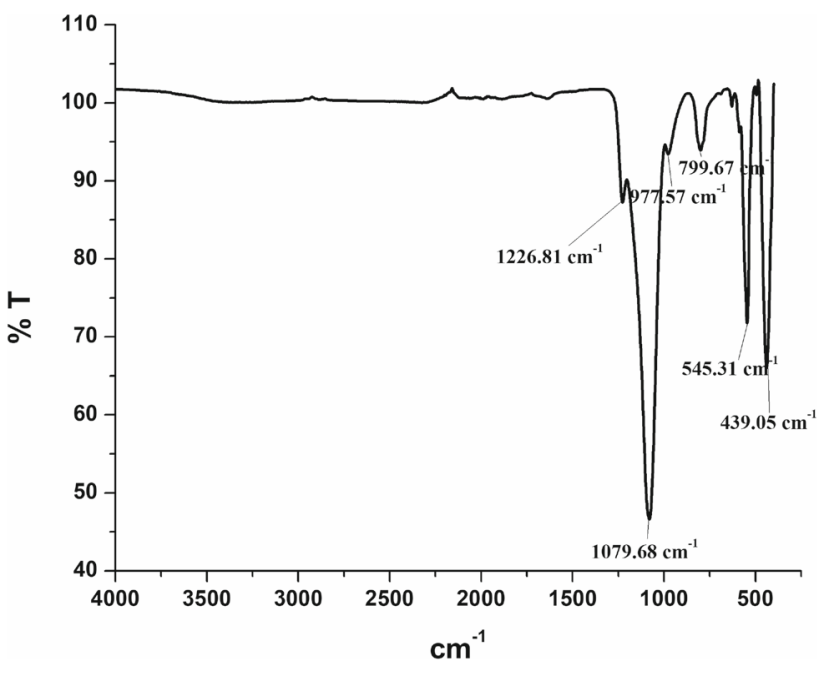

Figure 3. FTIR spectrum of Silicalite-1.

and in $18 \mathrm{~h}$ reaction time. Crystallinity was not much affected while using the seed to decrease the crystallization time. The seeding effect resulted in the pure and uniform sized crystals under the reduced crystallization time.

The XRD patterns of all samples showed five distinct peaks at $7.98^{\circ}, 8.87^{\circ}, 23.18^{\circ}, 23.98^{\circ}$, and $24.43^{\circ}$ corresponding to (101), (020), (501), (151), and (303) reflections which represent MFI structure. ${ }^{38,39}$ The average crystallite size of Silicalite- 1 and $\mathrm{Cu}$ loaded Silicalite1 calculated by Scherrer equation ${ }^{40-42}$ was found to be $40 \mathrm{~nm}$ and $64 \mathrm{~nm}$, respectively.

As shown in FE-SEM (Figure 2), individual crystals of 30-40 nm size were agglomerated to form clusters of approximately $150-200 \mathrm{~nm}$. The decrease in crystal size enhances the surface area with more number of active sites.

The FTIR spectra of nano-sized Silicalite-1 is shown in Figure 3. Vibration bands at 439.05, 799.67, 1079.68 and $1226.81 \mathrm{~cm}^{-1}$ were observed and assigned to
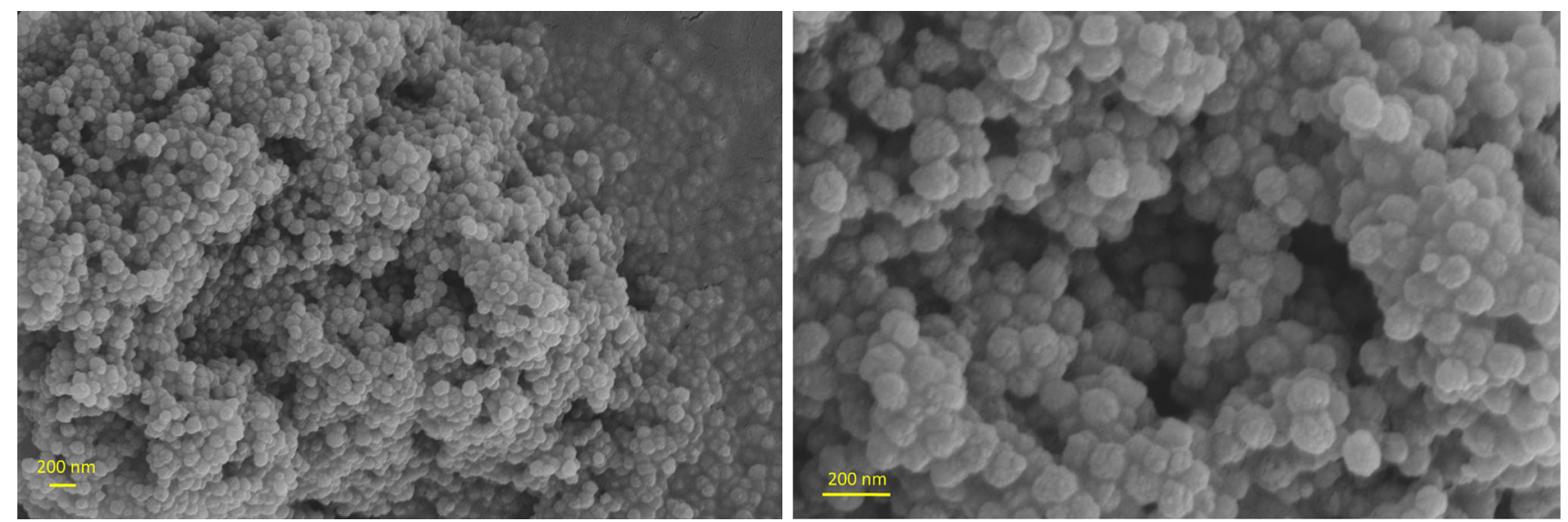

Figure 2. FE-SEM images of Silicalite-1. 


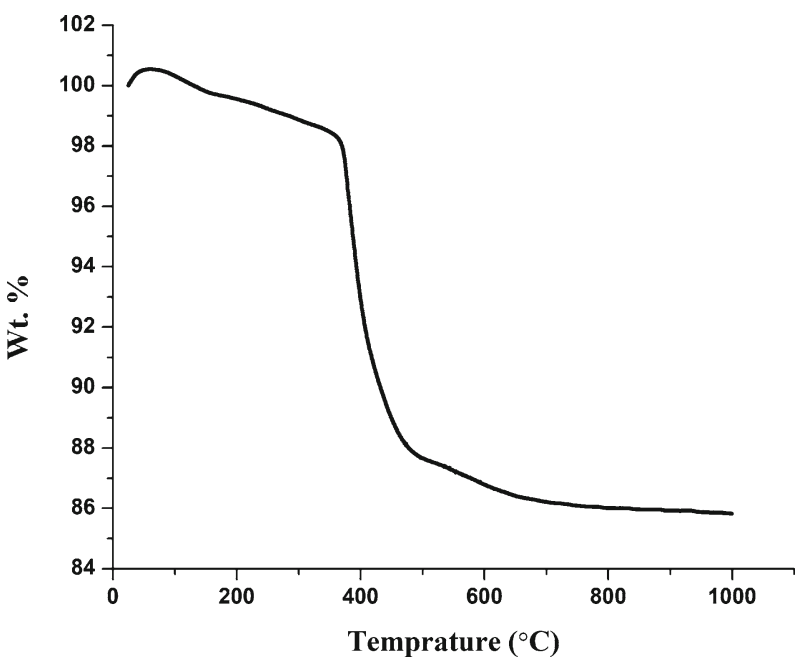

Figure 4. TG of Silicalite-1.

$\mathrm{Si}-\mathrm{O}-\mathrm{Si}$ bending, $\mathrm{Si}-\mathrm{O}-\mathrm{Si}$ symmetric stretching (outer $\mathrm{SiO}_{4}$ tetrahedron), Si-O-Si asymmetric stretching (inner $\mathrm{SiO}_{4}$ tetrahedron), and $\mathrm{Si}-\mathrm{O}-\mathrm{Si}$ asymmetric stretching (outer $\mathrm{SiO}_{4}$ tetrahedron) of a condensed silica network, respectively. The absorption peaks at around 977.57 and $545.31 \mathrm{~cm}^{-1}$ are assigned to the stretching vibration of the Si-OH group and MFI-structure, respectively. ${ }^{38,39}$
Thermal stability of as-synthesized catalyst was studied by thermogravimetric (TG) analysis. The TG curve (Figure 4) shows the initial weight loss of about $4.67 \%$ below $200{ }^{\circ} \mathrm{C}$ due to evaporation of physisorbed and structural water from the surface. The second weight loss of $9.82 \%$ between 350 and $560{ }^{\circ} \mathrm{C}$ is due to the decomposition of organic moieties within the framework. No significant weightloss was observed after $560{ }^{\circ} \mathrm{C}$, indicating good thermal stability of the material.

Physical properties such as BET surface area, micropore and mesopore area, micropore volume, total pore volume and average pore diameter of Silicalite- 1 and $\mathrm{Cu}$ loaded Silicalite-1 are reported in Table 2. Adsorption isotherm and pore size distribution of the samples are also compared in Figure 5. Copper loaded Silicalite-1 shows a decrease in surface area, pore volume and pore diameter compared to Silicalite-1 due to partial blocking of pores and surface by copper ions. The isotherms showing some mesoporosity with $\mathrm{H} 1$ type hysteresis loop at high pressure is not very common for microporous Silicalite-1 samples. However, it may be due to the presence of inter-particle void space between the elementary crystalline particles. Such type of H1/H4 type high-pressure hysteresis was observed in MFI phases by other researchers also resulting from swelling of microporous fissured regions or between large parallel crystal slabs. ${ }^{43,44}$

Table 2. Physical characteristics of Silicalite-1 and Cu Silicalite-1.

\begin{tabular}{lcccccc}
\hline Sample & $\begin{array}{l}\text { BET surface } \\
\text { area }\left(\mathrm{m}^{2} / \mathrm{g}\right)\end{array}$ & $\begin{array}{l}\text { Micropore } \\
\text { area }\left(\mathrm{m}^{2} / \mathrm{g}\right)\end{array}$ & $\begin{array}{l}\text { Mesopore area } \\
\left(\mathrm{m}^{2} / \mathrm{g}\right)\end{array}$ & $\begin{array}{l}\text { t-Plot micropore } \\
\text { volume }\left(\mathrm{cm}^{3} / \mathrm{g}\right)\end{array}$ & $\begin{array}{l}\text { Total pore } \\
\text { volume }\left(\mathrm{cm}^{3} / \mathrm{g}\right)\end{array}$ & $\begin{array}{l}\text { Average pore } \\
\text { diameter }(\AA)\end{array}$ \\
\hline Silicalite-1 & 350 & 239 & 111 & 0.12 & 0.25 & 131 \\
Cu Silicalite-1 & 277 & 201 & 76 & 0.10 & 0.20 & 121 \\
\hline
\end{tabular}
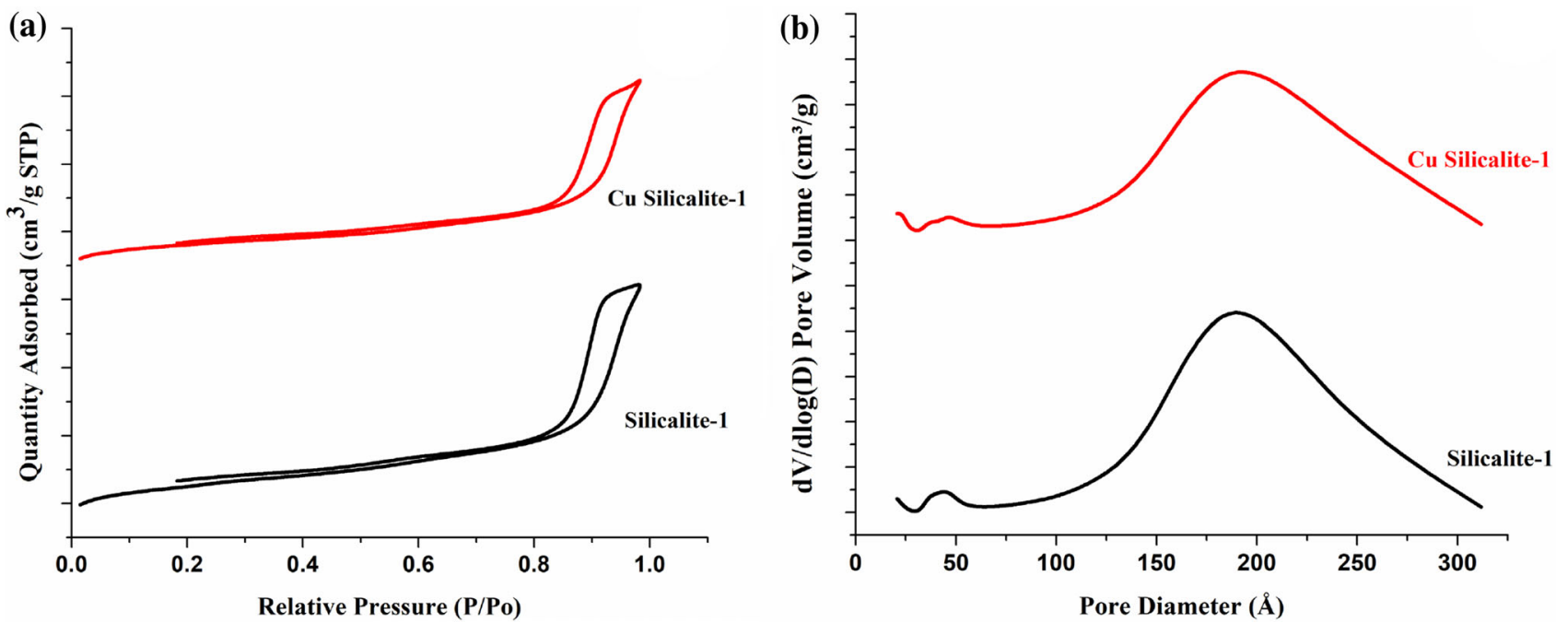

Figure 5. (a) $\mathrm{N}_{2}$ Adsorption-desorption isotherms and (b) BJH pore size distribution of Silicalite-1 and Cu Silicalite-1. 

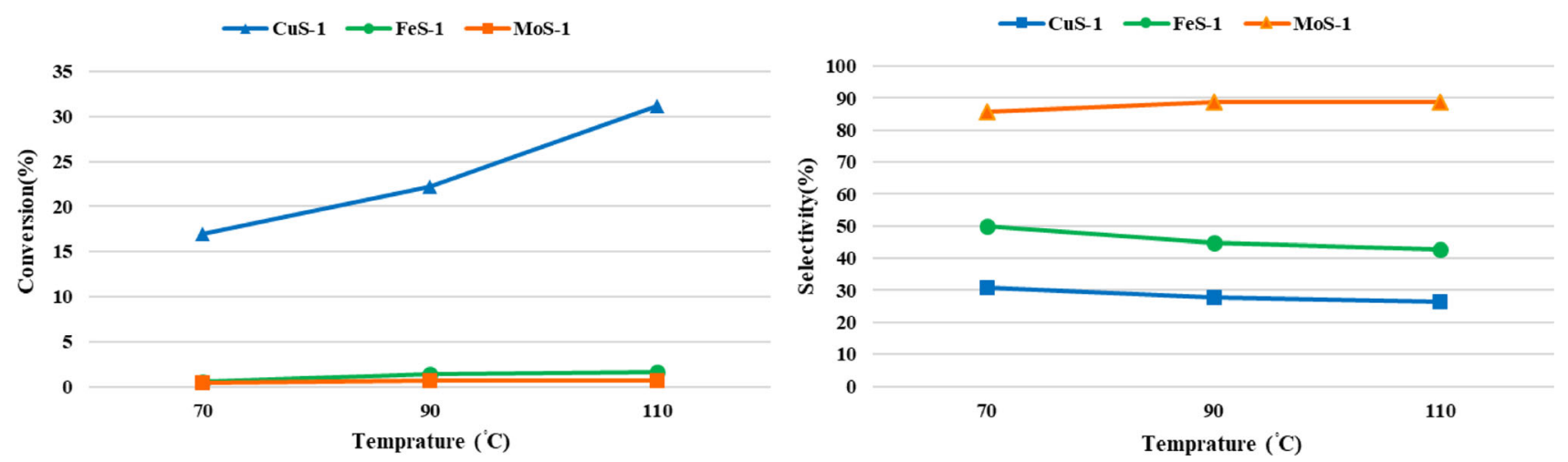

Figure 6. Selectivity and conversion at various temperature and metal loading ( $\mathrm{Cu}, \mathrm{Fe}$ and $\mathrm{Mo})$. Reaction conditions: Time $6 \mathrm{~h}, 0.2 \mathrm{~g}$ catalyst, Acetonitrile $12 \mathrm{~mL}$, Toluene $0.87 \mathrm{~mL}$, Toluene to $\mathrm{H}_{2} \mathrm{O}_{2}$ molar ratio 1:3.

Table 3. Effect of solvent on oxidation of toluene.

\begin{tabular}{lccr}
\hline Solvent & $\begin{array}{c}\text { Conversion of } \\
\text { toluene }(\%)\end{array}$ & \multicolumn{2}{c}{ Selectivity (\%) } \\
\cline { 3 - 4 } & 2.6 & Benzaldehyde & Others \\
\hline Water & 25.8 & 98.1 & 1.9 \\
Ethanol & 22.2 & 27.9 & 52.8 \\
Acetonitrile & 8.6 & 8.7 & 72.1 \\
DMSO & 7.0 & 0.9 & 91.3 \\
Cyclohexane & 1.9 & 39.7 & 99.1 \\
DMF & & & 60.3 \\
\hline
\end{tabular}

Reaction conditions: Time $6 \mathrm{~h}, 0.2 \mathrm{~g}$ catalyst, Solvent $12 \mathrm{~mL}$, Toluene $0.87 \mathrm{~mL}$, Toluene to $\mathrm{H}_{2} \mathrm{O}_{2}$ molar ratio 1:3.

\subsection{Catalytic activity of metal loaded nano-sized Silicalite-1 towards selective oxidation of toluene}

In order to get optimized catalyst in the selective oxidation of toluene, the reaction parameter was varied by studying the effect of different transition metal ions $(\mathrm{Cu}, \mathrm{Fe}$ and $\mathrm{Mo})$ loading on nano-sized Silicalite-1, catalyst amount $(0.1-0.3 \mathrm{~g})$, reaction temperature (70 $\left.110^{\circ} \mathrm{C}\right)$, time $(6-24 \mathrm{~h})$ and Toluene/ $\mathrm{H}_{2} \mathrm{O}_{2}$ molar ratio $(1: 1-1: 5)$.

The effect of impregnation of transition metal ions $(\mathrm{Cu}, \mathrm{Fe}$ and $\mathrm{Mo})$ on nano-sized Silicalite-1 in the reaction was studied by varying the temperature from $70^{\circ} \mathrm{C}$ to $110^{\circ} \mathrm{C}$. Figure 6 shows the influence of transition metal ions and temperature in the conversion of toluene and benzaldehyde selectivity. Iron and molybdenum impregnated nano-sized Silicalite-1 show very good selectivity towards benzaldehyde with very less conversion. On the other hand, copper impregnated nano-sized Silicalite-1 show very good conversion and good selectivity towards benzaldehyde. It is observed that the conversion of toluene increased from $17 \%$ to $31 \%$ with increasing the reaction temperature from $70^{\circ} \mathrm{C}$ to $110^{\circ} \mathrm{C}$. However, the selectivity of benzaldehyde decreased from $30.8 \%$ to $26.5 \%$. The low conversion of toluene at $70^{\circ} \mathrm{C}$ may be due to the thermal effect of kinetically controlled reaction. Thus, conversion of toluene increases with the increase in reaction temperature. It is considered that more by-products form due to an increase in temperature. To achieve optimum toluene conversion and benzaldehyde selectivity, $70{ }^{\circ} \mathrm{C}$ temperature and copper impregnated nano-sized Silicalite-1 as the catalyst was fixed for further evaluation of the catalyst.

The effect of solvents are shown in Table 3. The conversion of toluene was increased from $1.9 \%$ in a weak polar solvent such as DMF to $2.6 \%$ in a strong polar solvent such as water, and then to $22.2 \%$ in a medium polar solvent such as acetonitrile. In strong polar solvent like water, main oxidation product, benzaldehyde was $98.1 \%$, but the conversion was only $2.6 \%$. In weak polar solvents such as DMSO and DMF, the conversion was increased from $1.9 \%$ to $8.6 \%$, while selectivity was drastically decreased to $39.7 \%$ from $8.7 \%$. Significant conversion and selectivity $(22.2 \%$ and $27.9 \%$, respectively) were obtained in a medium polar solvent such as acetonitrile.

Other important factors, which influence the oxidation of toluene, are reaction time and catalyst amount. Figure 7 shows the effect of reaction time (6 h to $24 \mathrm{~h}$ ) 

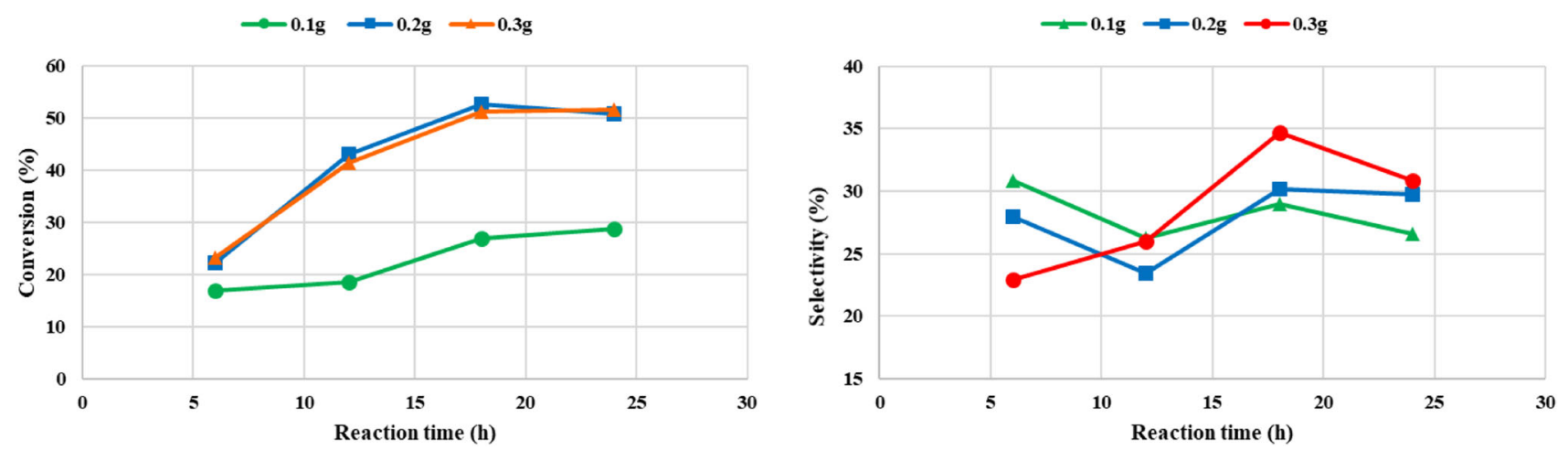

Figure 7. Effect of reaction time and amount of catalyst. Reaction conditions: Temperature $70{ }^{\circ} \mathrm{C}$, Toluene to $\mathrm{H}_{2} \mathrm{O}_{2}$ molar ratio 1:3, Acetonitrile $12 \mathrm{~mL}$, Toluene $0.87 \mathrm{~mL}$.
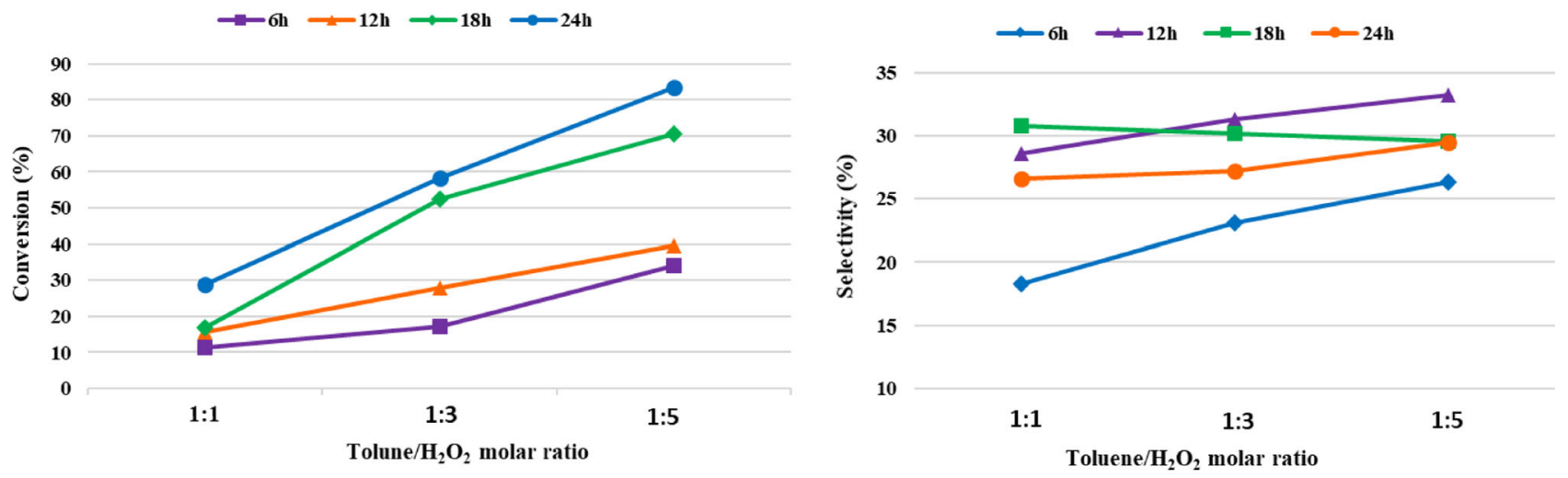

Figure 8. Effect of reaction time and Toluene $/ \mathrm{H}_{2} \mathrm{O}_{2}$ molar ratio. Reaction condition: Temperature $70^{\circ} \mathrm{C}$, catalyst $0.2 \mathrm{~g}$, Acetonitrile $12 \mathrm{~mL}$, Toluene $0.87 \mathrm{~mL}$.

and catalyst amount $(0.1 \mathrm{~g}$ to $0.3 \mathrm{~g})$ on the oxidation of toluene using copper impregnated nano-sized Silicalite-1. Conversion of toluene increases with the increase in reaction time and catalyst amount. No remarkable change was observed in the conversion of toluene with an increase in the reaction time further from $18 \mathrm{~h}$ to $24 \mathrm{~h}$. The conversion of toluene is lower with $0.1 \mathrm{~g}$ catalyst, which is due to insufficient active sites. However, with increasing the catalyst amount from $0.1 \mathrm{~g}$ to $0.3 \mathrm{~g}$, the conversion remarkably increased from $27 \%$ to $52 \%$. While taking $0.2 \mathrm{~g}$ and $0.3 \mathrm{~g}$ catalyst, no significant conversion difference was observed; therefore, $0.2 \mathrm{~g}$ catalyst and $18 \mathrm{~h}$ reaction time were considered as the ideal condition for optimizing the reaction parameters.

Influence of the molar ratio of Toluene/ $\mathrm{H}_{2} \mathrm{O}_{2}$ with respect to time on the oxidation of toluene was also studied by keeping other parameters constant (Figure 8). Conversion of toluene increased as reaction time increased in each set of molar ratio. The conversion of toluene was lower when toluene to $\mathrm{H}_{2} \mathrm{O}_{2}$ molar ratio was $1: 1$. This is due to complete utilization of $\mathrm{H}_{2} \mathrm{O}_{2}$ during the oxidation of toluene. When the molar ratio of toluene to $\mathrm{H}_{2} \mathrm{O}_{2}$ increased from $1: 1$ to $1: 5$, the conversion of toluene starts increasing. This result clearly indicates that conversion of toluene increases with increasing the amount of $\mathrm{H}_{2} \mathrm{O}_{2}$. This is due to the liberation of the high amount of oxygen on the decomposition of $\mathrm{H}_{2} \mathrm{O}_{2}$, which is responsible for oxidizing toluene. At the same time, an excess amount of liberated oxygen favors further oxidation of benzaldehyde that leads to the formation of benzoic acid. Therefore, the optimum molar ratio for this reaction was found to be $1: 3$.

Copper loaded Silicalite-1 was also tested for reusability in the oxidation of toluene at optimized reaction condition. In a typical experiment (after completion of each reaction) catalyst was recovered by centrifuge, washed with methanol, dried at $100^{\circ} \mathrm{C}$ for overnight and used two times. Figure 9 shows the catalytic activity after each reaction cycle. Conversion of toluene decreased to $33.3 \%$ from $52.6 \%$ and selectivity of benzaldehyde decreased to $17.4 \%$ from $30.2 \%$ after $2^{\text {nd }}$ cycle. The decrease in catalytic activity in the subsequent run may be due to partial metal leaching during the reaction and workup process. The XRD patterns (Figure S5, Supplementary Information) after each reaction revealed that the copper loaded Silicalite-1 retained its crystallinity throughout. 


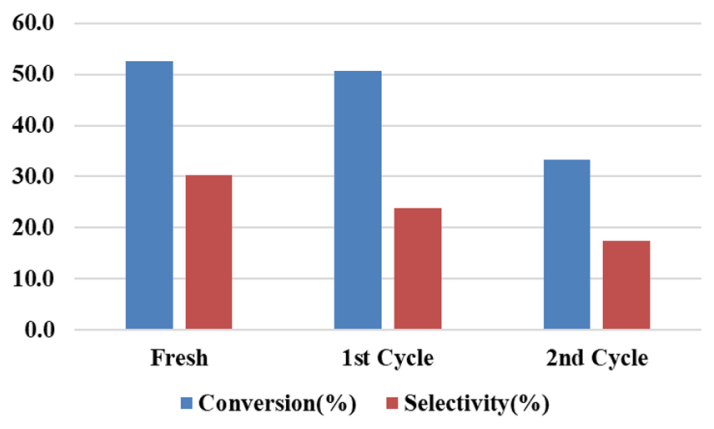

Figure 9. Catalyst reusability at optimized reaction conditions: Temperature $70^{\circ} \mathrm{C}$, catalyst $0.2 \mathrm{~g}$, Acetonitrile $12 \mathrm{~mL}$, Toluene $0.87 \mathrm{~mL}$, Toluene/ $\mathrm{H}_{2} \mathrm{O}_{2}$ molar ratio 1:3, Time $18 \mathrm{~h}$.

\section{Conclusions}

Nano-sized Silicalite-1 having MFI structure was successfully synthesized by a novel method using $\mathrm{H}_{3} \mathrm{PO}_{4}$ as a promoter. Structural, thermal, morphological and other characteristics of the catalyst were confirmed by using XRD, TG, FE-SEM and FTIR techniques. Effect of seed amount on crystal growth and crystallinity during the synthesis was found to be significant. Selective oxidation of toluene was found to be strongly influenced by the type of impregnated metal, reaction time, catalyst amount, temperature and toluene to $\mathrm{H}_{2} \mathrm{O}_{2}$ molar ratio. Copper impregnated nano-sized Silicalite-1 showed superior catalytic activity compared to its iron and molybdenum impregnated counterparts.

\section{Supplementary Information (SI)}

The results comprising effect of metal loading and reaction temperature on oxidation of toluene (Table S1); effect of reaction time and amount of catalyst (Table S2); effect of various reaction time, toluene to $\mathrm{H}_{2} \mathrm{O}_{2}$ molar ratio (Table S3), catalyst reusability (Table S4) and XRD patterns of reused catalyst (Figure S5) are available in Supplementary Information at www.ias.ac.in/chemsci.

\section{References}

1. Magano J and Dunetz J R 2012 Large-Scale Carbonyl Reductions in the Pharmaceutical Industry Org. Process Res. Dev. 161156

2. 2006 Final Report on the Safety Assessment of Benzaldehyde Int. J. Toxicol. 2511

3. Lv J, Shen Y, Peng L, Guo X and Ding W 2010 Exclusively selective oxidation of toluene to benzaldehyde on ceria nanocubes by molecular oxygen Chem. Commun. 465909

4. Kesavan L, Tiruvalam R, Rahim M H A, Saiman M I B, Enache D I, Jenkins R L, Nikolaos Dimitratos, LopezSanchez J A, Taylor S H, Knight D W, Kiely C J and
Hutchings G J 2011 Solvent-Free Oxidation of Primary Carbon-Hydrogen Bonds in Toluene Using Au-Pd Alloy Nanoparticles Science 331195

5. Martin A, Bentrup U and Wolf G-U 2002 The effect of alkali metal promotion on vanadium-containing catalysts in the vapour phase oxidation of methyl aromatics to the corresponding aldehydes Appl. Catal. Gen. 227 131

6. Tandon P K, Srivastava M, Kumar S and Singh S 2009 Iridium(III) catalyzed oxidation of toluene and ethyl benzene by cerium(IV) in aqueous acidic medium $J . M o l$. Catal. Chem. 304101

7. Balland V, Mathieu D, Pons-Y-Moll N, Bartoli J F, Banse F, Battioni P, Girerd J-J and Mansuy D 2004 Non-heme iron polyazadentate complexes as catalysts for oxidations by $\mathrm{H}_{2} \mathrm{O}_{2}$ : particular efficiency in aromatic hydroxylations and beneficial effects of a reducing agent J. Mol. Catal. Chem. 21581

8. Mardani H R and Golchoubian H 2006 Selective and efficient $\mathrm{C}-\mathrm{H}$ oxidation of alkanes with hydrogen peroxide catalyzed by a manganese(III) Schiff base complex $J$. Mol. Catal. Chem. 259197

9. Detoni C, Carvalho N M F, Aranda D A G, Louis B and Antunes O A C 2009 Cyclohexane and toluene oxidation catalyzed by 1,10-phenantroline $\mathrm{Cu}(\mathrm{II})$ complexes Appl. Catal. Gen. 365281

10. Ohkubo K, Suga K, Morikawa K and Fukuzumi S 2003 Selective Oxygenation of Ring-Substituted Toluenes with Electron-Donating and -Withdrawing Substituents by Molecular Oxygen via Photoinduced Electron Transfer J. Am. Chem. Soc. 12512850

11. Du Z, Sun Z, Zhang W, Miao H, Ma H and Xu J 2009 A free radical process for oxidation of hydrocarbons promoted by nonmetal xanthone and tetramethylammonium chloride under mild conditions Tetrahedron Lett. 501677

12. Ma B et al 2013 Solvent-free selective oxidation of CH bonds of toluene and substituted toluene to aldehydes by vanadium-substituted polyoxometalate catalyst $\mathrm{J}$. Mol. Catal. Chem. 368152

13. Monfared H H and Amouei Z 2004 Hydrogen peroxide oxidation of aromatic hydrocarbons by immobilized iron(III) J. Mol. Catal. Chem. 217161

14. Mac Leod T C O, Kirillova M V, Pombeiro A J L, Schiavon M A and Assis M D 2010 Mild oxidation of alkanes and toluene by tert-butylhydroperoxide catalyzed by an homogeneous and immobilized $\mathrm{Mn}$ (salen) complex Appl. Catal. Gen. 372191

15. Valodkar V B, Tembe G L, Ravindranathan M and Rama H S 2004 Catalytic oxidation of alkanes and alkenes by polymer-anchored amino acid-ruthenium complexes $J$. Mol. Catal. Chem. 22331

16. Saravanamurugan S, Palanichamy $\mathrm{M}$ and Murugesan V 2004 Oxyfunctionalisation of toluene with activated tbutyl hydroperoxide Appl. Catal. Gen. 273143

17. Mohapatra S and Selvam P 2007 A highly selective, heterogeneous route to enones from allylic and benzylic compounds over mesoporous CrMCM-41 molecular sieves J. Catal. 249394

18. Dumitriu D 2003 BiOx clusters occluded in a ZSM5 matrix: preparation, characterization, and catalytic behavior in liquid-phase oxidation of hydrocarbons $J$. Catal. 219337 
19. Dubey A and Mishra B G 2007 Selective liquid phase oxidation of aromatics over silica-polymer nanocomposite materials Catal. Commun. 81507

20. Vetrivel S and Pandurangan A 2004 Side-chain oxidation of ethylbenzene with tert-butylhydroperoxide over mesoporous Mn-MCM-41 molecular sieves J. Mol. Catal. Chem. 217165

21. Song G, Feng L, Xu J and Zhu H 2018 Liquid-phase oxidation of toluene to benzaldehyde with molecular oxygen catalyzed by copper nanoparticles supported on graphene Res. Chem. Intermed. 444989

22. Du B, Kim S-I, Lou L-L, Jia A, Liu G, Qi B and Liu S 2012 A simple and efficient zeolite catalyst for toluene oxidation in aqueous media Appl. Catal. Gen. 425 191

23. Li X, Lu B, Sun J, Wang X, Zhao J and Cai Q 2013 Selective solvent-free oxidation of toluene to benzaldehyde over zeolite supported iron Catal. Commun. 39115

24. Hammond $\mathrm{C}$ and Tarantino $\mathrm{G} 2015$ Switching off $\mathrm{H}_{2} \mathrm{O}_{2}$ Decomposition during TS-1 Catalysed Epoxidation via Post-Synthetic Active Site Modification Catalysts 5 2309

25. Yamaguchi S, Suzuki A, Togawa M, Nishibori M and Yahiro H 2018 Selective Oxidation of Thioanisole with Hydrogen Peroxide using Copper Complexes Encapsulated in Zeolite: Formation of a Thermally Stable and Reactive Copper Hydroperoxo Species ACS Catal. 8 2645

26. Liu J, Wang Z, Jian P and Jian R 2018 Highly selective oxidation of styrene to benzaldehyde over a tailor-made cobalt oxide encapsulated zeolite catalyst J. Colloid Interface Sci. 517144

27. Renz M, Blasco T, Corma A, Fornés V, Jensen R and Nemeth L 2002 Selective and Shape-Selective BaeyerVilliger Oxidations of Aromatic Aldehydes and Cyclic Ketones with Sn-Beta Zeolites and $\mathrm{H}_{2} \mathrm{O}_{2}$ Chem. A Eur. J. 84708

28. Peneau V, Armstrong R D, Shaw G, Xu J, Jenkins R L, Morgan D J, Dimitratos N, Taylor S H, Zanthoff H W, Peitz S, Stochniol G, He Q, Kiely C J and Hutchings G J 2017 The Low-Temperature Oxidation of Propane by using $\mathrm{H}_{2} \mathrm{O}_{2}$ and Fe/ZSM-5 Catalysts: Insights into the Active Site and Enhancement of Catalytic Turnover Frequencies ChemCatChem 9642

29. Mal N K, Ramaswamy V, Ganapathy S and Ramaswamy A V 1994 Synthesis and characterization of crystalline, tin-silicate molecular sieves with MFI structure J. Chem. Soc. Chem. Commun. 171933

30. Mal N K and Ramaswamy A V 1996 Oxidation of ethylbenzene over Ti-, V- and Sn-containing silicalites with MFI structure Appl. Catal. A Gen. 14375
31. Mal N K, Bhaumik A, Ramaswamy V, Belhekar A A and Ramaswamy A V 1995 Synthesis of Al-free Sn-containing molecular sieves of MFI, MEL and MTWtypes and their catalytic activity in oxidation reactions Stud. Surf. Sci. Catal. 94317

32. Bhaumik A and Kumar R 1995 Titanium Silicate Molecular Sieve (TS-1)/ $\mathrm{H}_{2} \mathrm{O}_{2}$ induced Triphase Catalysis in the Oxidation of Hydrophobic Organic Compounds with Significant Enhancement of Activity and ParaSelectivity J. Chem. Soc., Chem. Commun. 349

33. Hulea V, Dumitriu E, Patcas F, Ropot R, Graffin P and Moreau P 1998 Cyclopentene oxidation with $\mathrm{H}_{2} \mathrm{O}_{2}$ over Ti-containing zeolites Appl. Catal. A Gen. 170169

34. Čejka J and Mintova S 2007 Perspectives of Micro/Mesoporous Composites in Catalysis Catal. Rev. 49457

35. Tosheva L and Valtchev V P 2005 Nanozeolites: Synthesis, Crystallization Mechanism, and Applications Chem. Mater. 172494

36. Jacobsen C J H, Madsen C, Houzvicka J, Schmidt I and Carlsson A 2000 Mesoporous Zeolite Single Crystals J. Am. Chem. Soc. 1227116

37. Krishna R and Paschek D 2001 Molecular simulations of adsorption and siting of light alkanes in silicalite-1 Phys. Chem. Chem. Phys. 3453

38. Barot S, Nawab M and Bandyopadhyay R 2016 Alkali metal modified nano-silicalite-1: an efficient catalyst for transesterification of triacetin J. Porous Mater. 23 1197

39. Deng Y-Q, Yin S-F and Au C-T 2012 Preparation of Nanosized Silicalite-1 and Its Application in VaporPhase Beckmann Rearrangement of Cyclohexanone Oxime Ind. Eng. Chem. Res. 519492

40. Scherrer P 1918 Nachrichten von der Gesellschaft der Wissenschaften zu Göttingen MathematischPhysikalische Klasse. 298

41. Holzwarth U and Gibson N 2011 The Scherrer equation versus the "Debye-Scherrer equation." Nature Nanotechnol. 6534

42. Maniammal K, Madhu G and Biju V 2017 Xraydiffraction line profile analysis of nanostructured nickeloxide: Shape factor and convolution of crystallite size and microstrain contributions Physica E 85214

43. Ravishankar R, Kirschhock C, Schoeman B J, Vanoppen P, Grobet P J, Storck S, Maier W F, Martens J A, Schryver de F C and Jacobs P A 1998 Physicochemical Characterization of Silicalite-1 Nanophase Material J. Phys. Chem. B $\mathbf{1 0 2} 2633$

44. Llewellyn P L, Grillet Y, Patarin J and Faust A C 1993 On the physisorption isotherm of MFI-type zeolites: the high-pressure hysteresis Micropor. Mater. 1247 